\title{
SYNTHESIS AND EVALUATION OF SOME NEW 2-(5-(4-BENZAMIDOBENZYLIDENE)-2,4- DIOXOTHIAZOLIDIN-3-YL)ACETIC ACID ANALOGS AS ALDOSE REDUCTASE INHIBITORS
}

\author{
JYOTI PANDEY ${ }^{1,2}$, ARSHAD ALI ${ }^{2}$, ARUN KUMAR GUPTA ${ }^{3 *}$ \\ ${ }^{1}$ School of Pharmacy, Suresh Gyan Vihar University, Jaipur, Rajasthan, India. ${ }^{2}$ Department of Pharmaceutical Chemistry, Smriti College of \\ Pharmaceutical Sciences, Indore, Madhya Pradesh, India. ${ }^{3}$ Department of Pharmaceutical, RKDF Institute of Pharmaceutical Sciences, \\ Indore, Madhya Pradesh, India. Email: arunkg73@gmail.com \\ Received: 06 April 2016, Revised and Accepted: 10 October 2016
}

ABSTRACT

Objective: Aldose reductase (ALR) enzyme plays a significant role in conversion of excess amount of glucose into sorbitol in diabetic condition, inhibitors of which decrease the secondary complication of diabetes mellitus. Scarce treatment of diabetic complications has motivated our interest for the search of new aldose reductase inhibitors (ARIs) endowed with more favorable biological properties.

Methods: Newer (4-(benzamidobenzylidene)-2,4-dioxothiazolidin-3-yl) acetic acid derivatives were synthesized, and these compound were evaluated for their ARI and antidiabetic activity.

Results: ARI activity of synthesized compounds was found in the range of 57.8-71.9\% at 5 $\mu \mathrm{g} / \mathrm{mL}$. Similarly, synthesized compounds decrease blood glucose level in the range of $64.4-70.5 \mathrm{mg} / \mathrm{dl}$ at $15 \mathrm{mg} / \mathrm{kg}$ body weight.

Conclusion: (E)-2-(5-(4-(substituted benzamido)benzylidene)-2,4-dioxothiazolidin-3-yl)acetic acid analogs shows comparable ARI as well as antidiabetic activity. These new class of compounds might be address the diabetic complications with safety.

Keywords: Aldose reductase inhibitors, Diabetes mellitus, $N$-acetic acid-2,4-thiazolidinediones.

(C) 2017 The Authors. Published by Innovare Academic Sciences Pvt Ltd. This is an open access article under the CC BY license (http://creativecommons. org/licenses/by/4. 0/) DOI: http://dx.doi.org/10.22159/ajpcr.2017.v10i1.12073

\section{INTRODUCTION}

Diabetes mellitus (DM) have reached global pandemic proportions with India being designated "diabetes capital" of the world. DM is a multisystem disorder comprising metabolic and vascular abnormalities resulting from insulin deficiency, with or without insulin resistance. Diabetes is a prevalent, costly condition that causes significant illness, disability, and premature death. Insulin deficiency, in turn, leads to chronic hyperglycemia with disturbances of carbohydrate, fat, and protein metabolism. The diabetic complications and the United Kingdom prospective diabetes study demonstrated that strict and sustained control of glucose excursions through interventions including intensive insulin therapy reduces the risk of developing these complications in types 1 and 2 diabetes. However, relatively few diabetics have adopted this strict, physician monitored regimen, and this type of round-the-clock control is not practical for patients at large. During hyperglycemic event, the elevated glucose level enhances the activity of AR by increasing glucose flux through this pathway. Aldose reductase (ALR) contributes to the development of secondary diabetic complications. It is, therefore, believe to be a promising drug target. At present, there is no specific therapy available for diabetic complications. A metabolic approach is to control excess glucose flux in diabetic tissue through the first step of polyol pathway by aldose reductase inhibitors (ARIs) [1-5]

AR catalyzes the nicotinamide adenine dinucleotide phosphate (NADPH) dependent reduction of glucose into sorbitol in the first step of the polyol pathway, which further dehydrogenases through an $\mathrm{NAD}^{+}$dependent reaction into fructose [6,7]. The deprivation of NADPH and NAD+ and the intracellular accumulation of sorbitol result in biochemical imbalances which cause damage in target tissues. The oxidative stress triggered by the glucose oxidation process and increased ALR activity is considered to be a major mechanism responsible for the onset of diabetic complications [8,9]. A variety of ARIs have been reported; however, in clinical studies, many of them have exhibited low efficacy or a narrow spectrum of tissue activity, generally because of unfavorable pharmacokinetics, or have proved to produce toxic side-effects. At present, epalrestat is the only ARI available on the market [10-12]. Literature reveals that in the last few years, numerous 5-arylidene-2,4-thiazolidinediones derivatives produced appreciable ALR inhibition [13,14], but their effectiveness generally decreases in vivo, probably due to their poor penetrability to key target tissues, in particular, peripheral nerves [15-17]. Thus, the aim of this work to develop new ARIs, whit improved physicochemical properties and better bioavailability. In this study, new active analogs of 5-arylidene-2,4-dioxothiazolidines were identified and synthesized as potent in vitro ARI. In particular, 5-benzylidene moieties bearing methyl, methoxy, chloro, and/or dichloro substituted benzamido derivatives were prepared, which is potentially able to enhance stability of enzyme-inhibitor complex.

\section{METHODS}

All the chemicals used in the synthesis of designed compounds were of synthetic grade, and they were procured from Loba, Highmedia, and E. Merck. Thin layer chromatographic method was used for monitoring the progress of the reactions, thin layer chromatography (TLC) was performed using silica gel-G on glass plate in different solvent systems. Iodine vapor and UV detector (long wavelength) were used as detecting agents. The purification of intermediates and final compounds was carried out through recrystallization and column chromatography technique. For the purpose of chromatography glass column (high $18^{\prime \prime}$ with internal diameter $20 \mathrm{~mm}$ ), column grade silica gel mesh $\# 240-400$ as the stationary phase and appropriate solvent system as mobile phase were used. The melting points of synthesized compounds and intermediates were determined by open capillary method, which were uncorrected.

The absorption maxima $\left(\lambda_{\max }\right)$ of the intermediate and synthesized compounds were determined on Shimadzu 1700 UV-visual 
spectrophotometer by scanning the compound between 200 and $400 \mathrm{~nm}$ in methanol. The IR spectra of the intermediates and synthesized compounds were recorded on ABB spectrophotometer. The samples were sent to Central Drug Research Institute, Lucknow for mass spectrometry (MS), and nuclear magnetic resonance (NMR). Chemical shifts are given in d units (ppm) relative to internal standard tetramethylsilane and refer to dimethyl sulfoxide (DMSO)- $\mathrm{D}_{6}$ solutions.

\section{General method of synthesis}

Synthesis of (E)-2-(5-(4-nitrobenzylidene)-2,4-dioxothiazolidin3-yl)acetic acid derivatives $(C)$

Equimolar concentration of derivative of 4-nitro benzaldehyde $(0.025 \mathrm{~mol})$ and thiazolidinedione- $N$-acetic acid $(0.025 \mathrm{~mol})$ was taken in round-bottomed flask containing glacial acetic acid. To this, a catalytic amount of sodium acetate $(0.080 \mathrm{~g})$ was added. The reaction mixture was stirred and heated at $100-105^{\circ} \mathrm{C}$ for $10-12 \mathrm{hrs}$. Progress of the reaction mixture was checked through TLC. After completion of reaction, the mixture was kept aside for overnight at RT. The crystalline product was filtered, washed with cold acetic acid and used in next step (Scheme 1).

Synthesis of 2-(5-(4-aminobenzyl)-2,4-dioxothiazolidin-3-yl) acetic acid derivatives (D)

The crude compound C $(0.025 \mathrm{~mol})$ and granulated tin $(0.038 \mathrm{~mol})$ were taken in round-bottomed flask equipped with reflux condenser. $10 \mathrm{~mL}$ concentrated hydrochloric acid was added in step to control vigorous reaction. After complete addition of $\mathrm{HCl}$, the reaction mixture was heated on water bath and progress of the reaction mixture was checked through TLC. After completion of reaction gradually sodium hydroxide solution (7.5 g in $12 \mathrm{~mL}$ water) was added and amine was separated out.

\section{Synthesis of substituted benzoyl chloride (F1-F6)}

Different substituted benzoic acid derivatives $(0.01 \mathrm{~mol})$ were refluxed with thionyl chloride for 3-4 hrs, and the reaction was monitored through TLC. After completion of reaction, evaporate excess of thionyl chloride under reduced pressure, and the crude solid was used as such in next step (Scheme 2).

Synthesis of substituted 2-(5-(4-benzamidobenzyl)-2,4dioxothiazolidin-3-yl)acetic acid derivatives (G1-G6)

Substituted 2-(5-(4-benzamidobenzyl)-2,4-dioxothiazolidin-3-yl) acetic acid $(0.001 \mathrm{~mol})$ was taken in round-bottomed flask containing anhydrous dichloromethane. To this, a catalytic amount of triethylamine ( $0.001 \mathrm{~mol})$ was added. To the reaction mixture substituted benzoyl chloride was added slowly with constant stirring. The progress of the reaction mixture was checked through TLC. After evaporation of the solvent under reduced pressure, the crude solid was purified by column chromatography (Scheme 3).

\section{Biological evaluation of thiazolidinedione analogs}

In vitro biological evaluation

Enzyme preparation

A purified goat lens extract was prepared in accordance with the method of Hayman and Kinoshita with slight modifications [18]. Lenses were quickly removed from goat eye following euthanasia and homogenized (Glass-Potter) in 5 volume of cold deionized water. The homogenate was centrifuged at $10,400 \mathrm{rpm}$ at $0-4^{\circ}{ }^{\circ} \mathrm{C}$ for 30 minutes. Saturated ammonium sulfate solution was added to the supernatant fraction to form a $40 \%$ solution, which was stirred for 30 minutes at $0-4^{\circ} \mathrm{C}$ and then centrifuged at $10,400 \mathrm{rpm}$ for 20 minutes. Following this same procedure, the recovered supernatant was subsequently fractionated with saturated ammonium sulfate solution using first a $50 \%$, and then a $75 \%$ salt saturation. The precipitate recovered from the $75 \%$ saturated fraction, possessing ALR2 activity, was redissolved in $0.05 \mathrm{M} \mathrm{NaCl}$ and dialyzed overnight in $0.05 \mathrm{M} \mathrm{NaCl}$. The dialyzed material was used for the enzymatic assay.

\section{Enzymatic assay}

ALR2 activity was assayed at $30^{\circ} \mathrm{C}$ in a reaction mixture containing $0.75 \mathrm{~mL}$ of $10 \mathrm{mM}$ D,L-glyceraldehyde, $0.5 \mathrm{~mL}$ of $0.104 \mathrm{mM} \mathrm{NADPH}$, $0.75 \mathrm{~mL}$ of $0.1 \mathrm{M}$ sodium phosphate buffer ( $\mathrm{pH}=6.2$ ), $0.3 \mathrm{~mL}$ of enzyme extract, and $0.7 \mathrm{~mL}$ of deionized water in a total volume of $3 \mathrm{~mL}$. All the above reagents, except D,L-glyceraldehyde, were incubated at $30^{\circ} \mathrm{C}$ for 10 minutes; the substrate was then added to start the reaction, which was monitored for 5 minutes. Enzyme activity was calibrated by diluting the enzymatic solution to obtain an average reaction rate of $0.011 \pm 0.0010$ absorbance units/minute for the sample. AR percentage inhibitory activity of the synthesized compounds ( $15 \mu \mathrm{L}, 5 \mu \mathrm{g} / \mathrm{mL})$ was determined using same procedure.

\section{In vivo biological evaluation}

Induction of noninsulin dependent DM

The acclimatized animals were kept fasting for 24 hrs with water ad-libitm and $1 \% \mathrm{~W} / \mathrm{V}$ in saline of alloxan monohydrate (120 mg/kg i.p) was administered. After $1 \mathrm{hr}$ of alloxan administration, the animals were given ad-libitm. A 5\% dextrose solution was given in feeding bottle for a day to overcome the early hypoglycemic phase. The blood glucose regulator was monitored after alloxination by withdrawing a drop of blood from the tail vein by Tail tipping method. The blood was dropped on the dextrostix reagent pad. The strip was inserted into microprocessor digital blood glucometer and readings were noted.

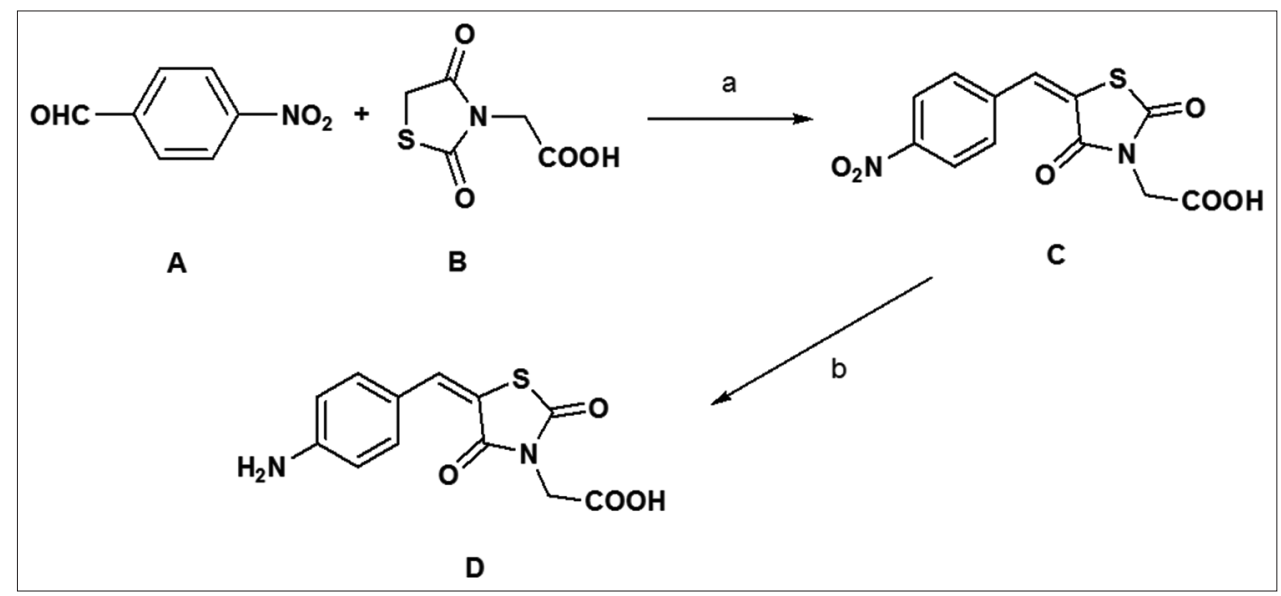

Scheme 1: General synthesis scheme of 2,4-dioxothiazolidin benzylidene derivatives. Reagents and conditions: $(\mathrm{a}) \mathrm{CH}_{3} \mathrm{COONa} \mathrm{CH}{ }_{3} \mathrm{COOH}$, Reflux; (b) T in granules, $\mathrm{HCl}$, Heat, $\mathrm{NaOH}$ 


\section{Experimental design}

Antidiabetic activity of the synthesized compounds was carried out in the group of 6 rats. Group 1 for diabetic control (Alloxan induced), Group 2 for reference standard (rosiglitazone $4 \mathrm{mg} / \mathrm{kg}$ body weight), and Group 3-8 for synthesized compounds $(15 \mathrm{mg} / \mathrm{kg}$ body weight for acute study). Antidiabetic activity of the synthesized compounds was test using alloxan induced diabetic model in albino rat. The dose of the synthesized compounds ( $15 \mathrm{mg} / \mathrm{kg}$ body weight) and rosiglitazone ( $4 \mathrm{mg} / \mathrm{kg}$ body weight) were administered orally in $2 \%$ acacia. The blood glucose level was monitored at different times $0,1,3$, and $6 \mathrm{hrs}$, respectively.

\section{RESULT AND DISCUSSION}

The analytical data of synthesized compounds are as follows:

(E)-2-(5-(4-benzamidobenzylidene)-2,4-dioxothiazolidin-3-yl) acetic acid G1

Practical yield and M.P. of the compound was found to be $60 \%$ and $238-240^{\circ} \mathrm{C}$, respectively. The $\lambda_{\max }$ of the compound was determined in methanol and it was found to be $350 \mathrm{~nm}$. G1 is soluble in DMSO, dimethylformamide (DMF), ethanol, acetone, methanol, and shows $R_{f}$ value 0.50 in $\mathrm{n}$-hexane:ethyl acetate $(3: 2)$ solvent system. IR $\left(\mathrm{cm}^{-1}\right)$ 2998 (C-H), 1595 and 1505 (aromatic C=C), 1160 (C-O), 1671 (amide $\mathrm{C}=0), 3397(\mathrm{O}-\mathrm{H})$; $1 \mathrm{H}$ NMR $\left(\mathrm{CDCl}_{3}\right)$ (d) $11.12(\mathrm{~s}, 1 \mathrm{H}, \mathrm{O}-\mathrm{H}), 8.10(\mathrm{~s}, 1 \mathrm{H}$, amide $\mathrm{NH}), 7.55-7.8(\mathrm{~m}, 5 \mathrm{H}$, arom. $\mathrm{CH}$; $1 \mathrm{H}$, ethylene $\mathrm{CH}), 7.28-7.44(\mathrm{~m}$, $4 \mathrm{H}$, arom. $\mathrm{CH}$ ), 3.88 (s, 2H, methylene); MS (ESI+): 405.7 [M+Na]+.

(E)-2-(5-(4-(2-chlorobenzamido)benzylidene)-2,4-dioxothiazolidin3-yl)acetic acid G2

Practical yield and M.P. of the compound was found to be $72 \%$ and $230^{\circ} \mathrm{C}$, respectively. The $\lambda_{\max }$ of the compound was determined in methanol and it was found to be $356 \mathrm{~nm}$. G2 is soluble in DMSO, DMF, ethanol, acetone, methanol, and shows $\mathrm{R}_{\mathrm{f}}$ value 0.55 in n-hexane: ethyl acetate (3:2) solvent system. IR $\left(\mathrm{cm}^{-1}\right) 3023(\mathrm{C}-\mathrm{H}), 1597$ and 1504 (aromatic C=C), 1149 (C-0), 1686 (amide C=0), 3399 (O-H), 777 (C-Cl);

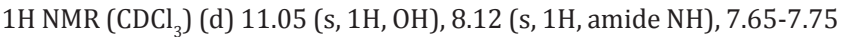
$(\mathrm{m}, 4 \mathrm{H}$, arom. $\mathrm{CH}$; $1 \mathrm{H}$, ethylene $\mathrm{CH}), 7.45-7.55(\mathrm{~m}, 4 \mathrm{H}$, arom. $\mathrm{CH}), 3.89$ (s, 2H, methylene); MS (ESI+): 439.7 [M+ Na]+.

(E)-2-(5-(4-(4-chlorobenzamido)benzylidene)-2,4-dioxothiazolidin3-yl)acetic acid G3

Practical yield and M.P. of the compound was found to be $52.6 \%$ and $235-237^{\circ} \mathrm{C}$, respectively. The $\lambda_{\max }$ of the compound was determined in methanol and it was found to be $348.5 \mathrm{~nm}$. G3 is soluble in DMSO, DMF, ethanol, acetone, methanol, and shows $\mathrm{R}_{\mathrm{f}}$ value 0.48 in $\mathrm{n}$-hexane: ethyl acetate (3:2) solvent system. IR (cm-1) 2994 (C-H), 1587 and 1505

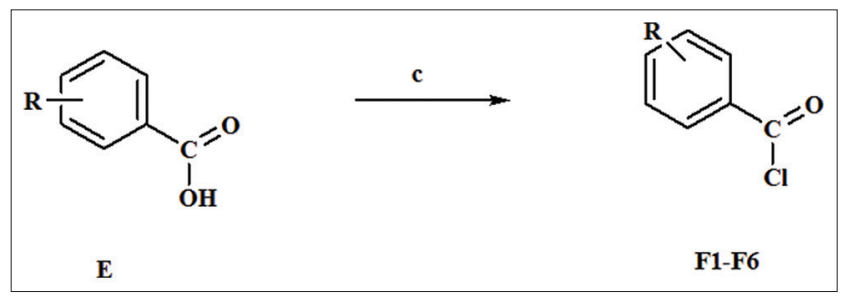

Scheme 2: General synthesis scheme of benzyl chloride derivatives. Reagents and conditions: (c) $\mathrm{SOCl}_{2}$, Reflux (aromatic $\mathrm{C}=\mathrm{C}$ ), 1277 (C-0), 1672 (amide $\mathrm{C}=0), 1600(\mathrm{O}-\mathrm{H}), 769$ (C-Cl); $1 \mathrm{H} \mathrm{NMR}\left(\mathrm{CDCl}_{3}\right)$ (d) $11.04(\mathrm{~s}, 1 \mathrm{H}, \mathrm{OH}), 8.02$ (s, $1 \mathrm{H}$, amide $\left.\mathrm{NH}\right), 7.59-7.28$ (m, 4H, arom. CH; $1 \mathrm{H}$, ethylene $\mathrm{CH}$ ), 7.89-7.61 (m, 4H, arom. $\mathrm{CH}$ ), 3.91 (s, 2H, methylene); MS (ESI+): 439.7 [M+Na]+.

\section{(E)-2-(5-(4-(3,4-dichlorobenzamido)benzylidene)-2,4-dioxothiazolidin-} 3-yl)acetic acid G4

Practical yield and M.P. of the compound was found to be $53 \%$ and 225 $227^{\circ} \mathrm{C}$ (D), respectively. The $\lambda_{\max }$ of the compound was determined in methanol and it was found to be $335 \mathrm{~nm}$. G4 is soluble in DMSO, DMF, ethanol, acetone, methanol, and shows $\mathrm{R}_{\mathrm{f}}$ value 0.52 in $\mathrm{n}$-hexane: ethyl acetate (3:2) solvent system. IR $\left(\mathrm{cm}^{-1}\right) 2984(\mathrm{C}-\mathrm{H}), 1597$ and 1508 (aromatic C=C), 1267 (C-O), 1718 (C=0), $3390(\mathrm{O}-\mathrm{H}), 759$ (C-Cl); 1H NMR (DMSO) (d) $11.04(\mathrm{~s}, 1 \mathrm{H}, \mathrm{OH}), 7.61-7.29(\mathrm{~m}, 4 \mathrm{H}$, arom. $\mathrm{CH} ; 1 \mathrm{H}$, ethylene $\mathrm{CH}), 8.05-7.71(\mathrm{~m}, 3 \mathrm{H}$, arom. $\mathrm{CH}$; $1 \mathrm{H}$, amide $\mathrm{NH}), 3.91(\mathrm{~s}, 2 \mathrm{H}$, methylene); MS (ESI+): $473.1[\mathrm{M}+\mathrm{Na}]+$.

(E)-2-(5-(4-(2-methylbenzamido)benzylidene)-2,4-dioxothiazolidin3-yl)acetic acid G5

Practical yield and M.P. of the compound was found to be $56 \%$ and $230-232^{\circ} \mathrm{C}$ (D), respectively. The $\lambda_{\max }$ of the compound was determined in methanol and it was found to be $339 \mathrm{~nm}$. G5 is soluble in DMSO, DMF, ethanol, acetone, methanol, and shows $\mathrm{R}_{\mathrm{f}}$ value 0.52 in $\mathrm{n}$-hexane: ethyl acetate (3:2) solvent system. IR $\left(\mathrm{cm}^{-1}\right) 2965(\mathrm{C}-\mathrm{H}), 1603$ and 1505 (aromatic C=C), 1174 (C-O), 1666 (amide C=0), 3314 (O-H); 1H NMR (DMSO) (d) $11.00(\mathrm{~s}, 1 \mathrm{H}, \mathrm{OH}), 8.03$ (s, $1 \mathrm{H}$, amide $\mathrm{NH}), 7.71-7.28(\mathrm{~m}, 8 \mathrm{H}$, arom. $\mathrm{CH}$; $1 \mathrm{H}$, ethylene $\mathrm{CH}$ ), 3.91 (s, $2 \mathrm{H}$, methylene); 2.39 (s, 3H, Methyl $\mathrm{CH}), \mathrm{MS}(\mathrm{ESI}+)$ : $419.1[\mathrm{M}+\mathrm{Na}]+$.

(E)-2-(5-(4-(4-methoxybenzamido)benzylidene)-2,4-dioxothiazolidin3-yl)acetic acid G6

Practical yield and M.P. of the compound was found to be $70.5 \%$ and $235^{\circ} \mathrm{C}$ (D), respectively. The $\lambda_{\max }$ of the compound was determined in methanol and it was found to be $347 \mathrm{~nm}$. G6 is soluble in DMSO, DMF, ethanol, acetone, methanol, and shows $\mathrm{R}_{\mathrm{f}}$ value 0.44 in n-hexane: ethyl acetate (3:2) solvent system. IR ( $\left.\mathrm{cm}^{-1}\right) 3077(\mathrm{C}-\mathrm{H}), 1593$ and 1509 (aromatic C=C), 1165 (C-O), 1677 (amide $\mathrm{C}=0$ ), 3440 (O-H), 1204 (-OCH3); 1H NMR (DMSO) (d) 11.01 (s, 1H, OH), 8.03 (s, 1H, amide NH), 7.81-7.08 (m, 8H, arom. CH; $1 \mathrm{H}$, ethylene $\mathrm{CH}), 3.98$ (s, 2H, methylene); 3.83 (s, 3H, Methoxy CH); MS (ESI+):435.2 [M+Na]+.

The structure of synthesized compounds was supported by ${ }^{1} \mathrm{H}$ NMR, MASS spectral data, and IR findings. All spectral data were in accordance with assumed structures. Spectral study revealed that synthesized compound having anticipated structure (Table 1).

\section{ARI}

All the synthesized 2,4-dioxothiazolidin-3-yl acetic acid derivatives were evaluated for their ability to inhibit the in vitro reduction of D,Lglyceraldehydes by partially purified ALR from goat lenses; sorbinil was used as a reference drug (Table 2 and Fig. 1). Inhibitory data indicate that 2-substitution on benzamido moiety shows more potent inhibitory activity as compare to un-substituted, 4-substituted or 3,4 di-substituted analogs.

\section{In vivo biological evaluation}

All the synthesized thiazolidinedione also evaluated for their antidiabetic activity using rosiglitazone as reference drug. The decrease in blood glucose level against each compound is shown in Table 3 and

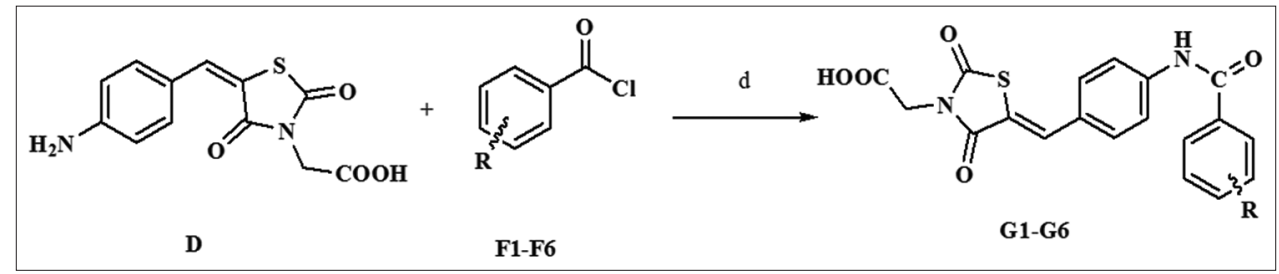

Scheme 3: General synthesis scheme of substituted benzylidene 2,4-dioxothiazolidin derivatives. Reagents and conditions: $(\mathrm{d}) \mathrm{CH}_{2} \mathrm{Cl}_{2}$, $\left(\mathrm{C}_{2} \mathrm{H}_{5}\right) 3 \mathrm{~N}$, stirring 
Table 1: Structure, molecular weight, percentage yield, and retardation factor $\left(\mathrm{R}_{\mathrm{f}}\right)$ of synthesized $N$-acetic acid thiazolidinedione analogs

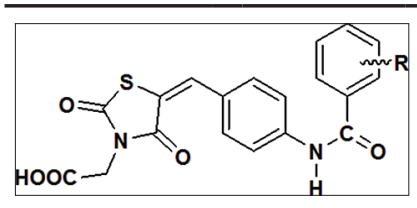

\begin{tabular}{lllll}
\hline Compound no. & R & MW & \% Yield & $\mathbf{R}_{\mathbf{f}}$ value \\
\hline G1 & $\mathrm{H}$ & 383.37 & 60 & 0.50 \\
G2 & $2-\mathrm{Cl}$ & 397.4 & 55 & 0.55 \\
G3 & $4-\mathrm{Cl}$ & 452.26 & 52.6 & 0.48 \\
G4 & 3,4 dichloro & 417.82 & 72 & 0.52 \\
G5 & $2-\mathrm{CH}_{3}$ & 397.4 & 56 & 0.52 \\
G6 & $4-\mathrm{OCH}_{3}$ & 413.4 & 70.5 & 0.44 \\
\hline
\end{tabular}

Table 2: Aldose reductase percentage inhibitory activity of synthesized $N$-acetic acid-2,4- thiazolidinedione analogs

\begin{tabular}{ll}
\hline Compound & \% Inhibition ( $\mathbf{s}$ standard) \\
\hline Standard (Sorbinil) & $70 \pm 4.1$ \\
G1 & $57.87 \pm 8.25$ \\
G2 & $69.43 \pm 6.42$ \\
G3 & $52.97 \pm 6.72$ \\
G4 & $47.57 \pm 7.87$ \\
G5 & $71.96 \pm 1.98$ \\
G6 & $67.46 \pm 3.45$ \\
\hline
\end{tabular}

Table 3: Antidiabetic activities of the synthesized $\mathrm{N}$-acetic acid-2,4-thiazolidinedione analogs

\begin{tabular}{llll}
\hline Compound & \multicolumn{3}{l}{ Decrease in blood glucose level $\mathbf{~ m g} / \mathbf{d l}$} \\
\cline { 2 - 4 } & ${ }^{\mathrm{a}} \mathbf{1} \mathbf{~ h r}$ & ${ }^{\mathrm{a}} \mathbf{3} \mathbf{~ h r s}$ & ${ }^{\mathrm{a}} \mathbf{6 ~ h r s}$ \\
\hline Control & $3.81 \pm 2.40$ & $8.00 \pm 3.96$ & $17.59 \pm 3.54$ \\
Standard & $23.31 \pm 21.08^{* *}$ & $38.39 \pm 27.88^{* *}$ & $58.42 \pm 16.72^{* *}$ \\
(roziglitazone) & & & \\
G1 & $17.25 \pm 3.91^{*}$ & $35.67 \pm 7.37^{* *}$ & $64.41 \pm 3.04^{* *}$ \\
G2 & $28.83 \pm 2.46^{* *}$ & $41.78 \pm 6.79^{* *}$ & $69.18 \pm 2.70^{* *}$ \\
G3 & $27.80 \pm 4.08^{* *}$ & $44.29 \pm 6.39^{* *}$ & $70.21 \pm 1.66^{* *}$ \\
G4 & $22.77 \pm 2.78^{* *}$ & $42.34 \pm 3.31^{* *}$ & $69.37 \pm 1.40^{* *}$ \\
G5 & $23.99 \pm 1.72^{* *}$ & $44.48 \pm 5.34^{* *}$ & $70.51 \pm 3.46^{* *}$ \\
G6 & $20.50 \pm 3.15^{* *}$ & $45.52 \pm 15.27^{* *}$ & $65.94 \pm 3.66^{* *}$ \\
\hline
\end{tabular}

${ }^{a}$ Mean \pm SEM $(n=6) ;{ }^{*}<<0.05 ;{ }^{* *} \mathrm{p}<0.01$. SEM: Standard error of mean

Fig. 2. Inhibitory data indicate that the synthesized compounds show better activity than reference compound.

\section{CONCLUSION}

$\mathrm{N}$-acetic acid thiazolidinedione with various substitutions on benzylidene moiety were studied. Synthesized compound shows ARI activity in the range of 57.8-71.9\%. The compound with 3,4 dichloro substitution on benzamido moiety (G4) shows minimum inhibition as compared to other analogs. In particular, 2-methyl substituted derivative (G5) proved to be the most active among these substituted compounds. The electron withdrawing group ( 3 and 4 position) shows less potency as compare to electron releasing group. The substitution on second position with electron releasing group is more favorable. Di-substitution on aromatic ring reduces the activity as compare to monosubstituted analogs. In vivo study of $\mathrm{N}$-acetic acid, thiazolidinedione derivatives were carried out by alloxan induced tail tipping method. Synthesized compound shows decrease in blood glucose level in the range of $35.6-45.5 \%$ after $3 \mathrm{hrs}$ while $64.4-70.5 \%$ after 6 hrs. The activity data of all compounds have $p<0.001$ after 6 hrs. Preliminary antidiabetic activity study and structure of TZD analogs are unable to explain any SAR.

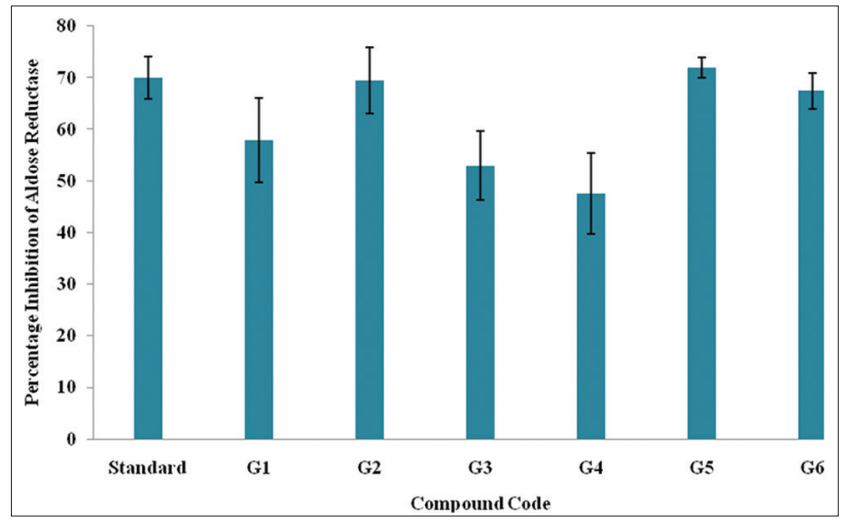

Fig. 1: Graphical representation of aldose reductase inhibitory activity of $\boldsymbol{N}$-acetic acid-2,4-thiazolidinedione analogs

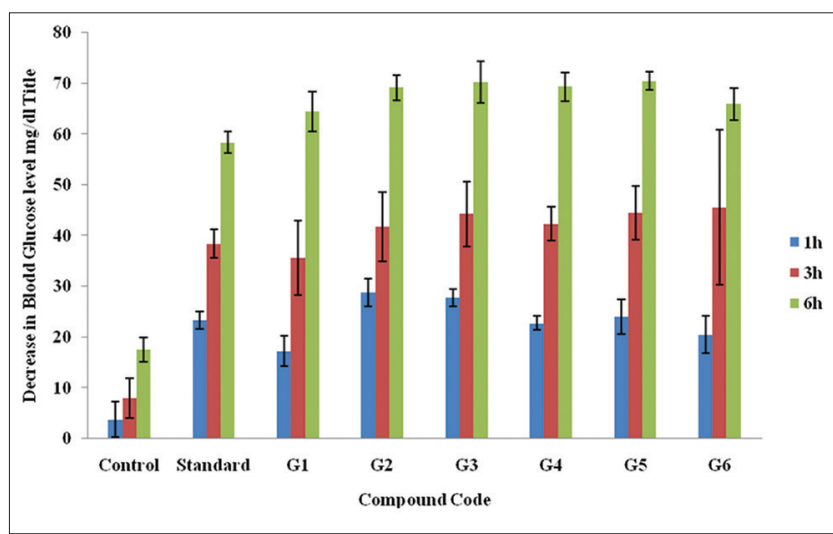

Fig. 2: Graphical representation of antidiabetic activity of $\mathrm{N}$-acetic acid-2,4-thiazolidinedione analogs

This study has resulted in the identification of (E)-2-(5-(4-(substituted benzamido)benzylidene)-2,4-dioxothiazolidin-3-yl)acetic acid analogs as ARI and antidiabetic agents. These new class of compounds might be address the diabetic complications with safety.

\section{REFERENCES}

1. Bastaki S. Diabetes mellitus and its treatment. Int J Diabetes Metab 2005; 13:111-34.

2. Intensive blood-glucose control with sulphonylureas or insulin compared with conventional treatment and risk of complications in patients with Type 2 diabetes (UKPDS 33). UK Prospective Diabetes Study (UKPDS) Group. Lancet 1998;352(9131):837-53.

3. Anil Kumar P, Bhanuprakash Reddy G. Focus on molecules: Aldose reductase. Exp Eye Res 2007;85(6):739-40

4. Mansour MA. Aldose reductase in the retina. Curr Enzym Inhib 2007;3:49-60.

5. Agrawal YP, Agrawal MY, Gupta AK. Emerging molecular targets for the treatment and management of diabetes mellitus - A review. Int J Pharm Sci 2013;5:2000-15.

6. Yabe-Nishimura C. Aldose reductase in glucose toxicity: A potential target for the prevention of diabetic complications. Pharmacol Rev 1998;50(1):21-33.

7. Srivastava SK, Ramana KV, Bhatnagar A. Role of aldose reductase and oxidative damage in diabetes and the consequent potential for therapeutic options. Endocr Rev 2005;26(3):380-92.

8. Brownlee M. The pathobiology of diabetic complications: A unifying mechanism. Diabetes 2005;54(6):1615-25.

9. Agrawal YP, Agrawal MY, Gupta AK. Design, synthesis and evaluation of rhodanine derivatives as aldose reductase inhibitors. Chem Biol Drug Des 2015;85(2):172-80.

10. Costantino L, Rastelli G, Vianello P, Cignarella G, Barlocco D. Diabetes complications and their potential prevention: Aldose reductase inhibition and other approaches. Med Res Rev 1999;19(1):3-23. 
11. Costantino L, Rastelli G, Gamberini MC, Barlocco D. Pharmacological approaches to the treatment of diabetic complications. Expert Opin Ther Patents 2000;10(8):1245.

12. Castaner J, Prous J. Monograph: Epalrestat. Drugs Future 1987;12:336.

13. Bruno G, Costantino L, Curinga C, Maccari R, Monforte F, Nicoló F, et al. Synthesis and aldose reductase inhibitory activity of 5-arylidene2,4-thiazolidinediones. Bioorg Med Chem 2002;10(4):1077-84.

14. Maccari R, Ottanà R, Curinga C, Vigorita MG, Rakowitz D, Steindl T, et al. Structure-activity relationships and molecular modelling of 5-arylidene-2,4-thiazolidinediones active as aldose reductase inhibitors. Bioorg Med Chem 2005;13(8):2809-23.

15. Maccari R, Ottanà R, Ciurleo R, Vigorita MG, Rakowitz D, Steindl T, et al. Evaluation of in vitro aldose redutase inhibitory activity of 5-arylidene-2,4-thiazolidinediones. Bioorg Med Chem Lett 2007;17(14):3886-93.

16. Lee YS, Hodoscek M, Kador PF, Sugiyama K. Hydrogen bonding interactions between aldose reductase complexed with $\mathrm{NADP}(\mathrm{H})$ and inhibitor tolrestat studied by molecular dynamics simulations and binding assay. Chem Biol Interact 2003;143-144:307-16.

17. El-Kabbani O, Ruiz F, Darmanin C, Chung RP. Aldose reductase structures: Implications for mechanism and inhibition. Cell Mol Life Sci 2004;61(7-8):750-62.

18. Da Settimo F, Primofiore G, La Motta C, Salerno S, Novellino E, Greco G, et al. Spirohydantoin derivatives of thiopyrano[2,3-b]pyridin$4(4 \mathrm{H})$-one as potent in vitro and in vivo aldose reductase inhibitors. Bioorg Med Chem 2005;13(2):491-9. 